\title{
Relação Ca:Mg do corretivo da acidez do solo e as características agronômicas de plantas forrageiras
}

\author{
Calcium:magnesium ratio amendments of soil acidity and agronomy characteristics of \\ forage specie
}

\section{GUIMARÃES JÚNIOR, Marim Paulo Alves ${ }^{1}$; SANTOS, Antonio Clementino dos ${ }^{1}$; ARAÚJO, Aridouglas dos Santos ${ }^{1 *}$; OLIVEIRA, Leonardo Bernardes Taverny de ${ }^{1}$; RODRIGUES, Marcos Odilon Dias ${ }^{1}$; MARTINS, Athila Damasceno ${ }^{1}$}

\footnotetext{
${ }^{1}$ Universidade Federal do Tocantins Araguaína, Tocantins, Brasil.

*Endereço para correspondência: aridouglas@uft.edu.br
}

\section{RESUMO}

A variação na relação $\mathrm{Ca}: \mathrm{Mg}$ em corretivos da acidez do solo é a principal forma de alterar a disponibilidade desses nutrientes para as espécies forrageiras. O objetivo com o trabalho foi avaliar o efeito de diferentes proporções entre cálcio e magnésio na forma de $\mathrm{CaCO}_{3}$ e $\mathrm{MgCO}_{3}$ sobre as propriedades químicas do solo e as características agronômicas de espécies forrageiras em Araguaína, TO. O estudo foi sobre Neossolo Quartzarênico Órtico típico, com 5\% de argila, com fatorial 3 x 5, sendo três as espécies forrageiras (Brachiaria brizantha cv. Xaraés, Panicum maximum cv: Mombaça e estilosante Campo Grande - Stylosanthes capitata e S. macrocephala) e cinco as relações de $\mathrm{Ca}: \mathrm{Mg}$ no calcário $(1: 1 ; 2: 1 ; 4: 1,6: 1$ e 8:1). Os tratamentos foram dispostos em delineamento em blocos ao acaso, com quatro repetições. Todos os tratamentos receberam dose equivalente de $4 \mathrm{t} / \mathrm{ha}$ de calcário. As diferentes relações $\mathrm{Ca}: \mathrm{Mg}$ influenciaram no desenvolvimento e produtividade das forrageiras entretanto, não se obteve comportamento coerente que indicasse a tendência de resposta das plantas ao aumento ou redução da relação Ca:Mg. Além disto, as diferentes forrageiras foram semelhantes em relação a química do solo, porém as relações $\mathrm{Ca}: \mathrm{Mg}$ alteraram as propriedades químicas do solo.

Palavras-chave: calagem, fertilidade do solo, gramínea, leguminosa, nutrientes

\section{SUMMARY}

The variation in the Ca: $\mathrm{Mg}$ ratio in amendments used to neutralize soil acidity is way of altering the availability of those nutrients in forage species and properties soil chemists. The objective of work was to evaluate the effect of different proportions of calcium and magnesium in of $\mathrm{CaCO}_{3}$ and $\mathrm{MgCO}_{3}$ on agronomy characteristics on soil chemist properties in forage species in Araguaína city, Tocantins state. The study was carried on Entisol, with factorial $3 \times 5$ and four replications. The treatments had consisted of ratio application equivalent the $4 \mathrm{t} / \mathrm{ha}$ of calcareous, using mixtures of $\mathrm{CaCO}_{3}$ and $\mathrm{MgCO}_{3}$ in diverse ratios until reaching relations $\mathrm{Ca}: \mathrm{Mg}$ of $1: 1 ; 2: 1 ; 4: 1,6: 1$ and 8:1, applied in Entisol, with 5\% of clay, cultivated with three forages species (Brachiaria brizantha cv. Xaraés, Panicum maximum cv: Mombaça e Stylosanthes Campo Grande - Stylosanthes capitata e S. macrocephala). The different relations $\mathrm{Ca}: \mathrm{Mg}$ was however influenced in development and productivity of forages, however was not coherent behavior that indicated the trend of reply of the plants to the increase or reduction of the relation $\mathrm{Ca}: \mathrm{Mg}$. Moreover, the different forages were been similar in relation the soil chemistry, however the relations $\mathrm{Ca}: \mathrm{Mg}$ had modified the chemical soil properties.

Keywords: grass, legume, liming, nutrients, soil fertility 


\section{INTRODUÇÃO}

O solo do cerrado e de transição com a Amazônia apresenta topografia favorável, facilitando a mecanização, por outro lado, são solos extremamente pobres (Neossolos Quartzarênico Órtico) e ácidos (Latossolos Amarelo), devido à sua natureza e formação (EMBRAPA, 2006), tornando-se necessária adequada caracterização que possibilite a recomendação de práticas que melhorem ou mantenham as condições de sustentabilidade desses solos.

A correção da acidez do solo, por meio da calagem $\left(\mathrm{CaCO}_{3}\right.$ e $\left.\mathrm{MgCO}_{3}\right)$, levando em consideração a relação $\mathrm{Ca}: \mathrm{Mg}$ contribui de forma relevante para o aumento da produtividade das forrageiras em virtude de melhoria nas propriedades químicas, físicas $\mathrm{e}$ biológicas do solo (FREIRIA et al., 2008; BARRETO et al., 2008).

Os problemas relacionados com a nutrição de plantas são corrigidos, geralmente, mediante a modificação da disponibilidade de nutrientes com a aplicação de corretivos e fertilizantes, por esses solos apresentarem, na maioria das vezes, baixa fertilidade natural ou toxidez de certos elementos (MALAVOLTA, 2008).

A aplicação de calcário para correção da acidez depende de vários fatores, tais como dose do corretivo, granulometria e reatividade do calcário, frequência da calagem, tempo transcorrido após a calagem, poder tampão do solo e precipitação pluvial (MIRANDA et al., 2005).

Os mecanismos para explicar o efeito de neutralização da acidez em profundidade, pela aplicação de calcário na superfície, segundo Caíres et al. (2000) são: a formação e a migração de $\mathrm{Ca}\left(\mathrm{HCO}_{3}\right)_{2}$ e $\mathrm{Mg}\left(\mathrm{HCO}_{3}\right)_{2}$ para camadas mais profundas do solo, e o deslocamento de partículas de calcário por meio de canais formados por raízes mortas mantidos intactos em razão da ausência de preparo de solo.

A máxima alteração das características químicas do solo de acordo com Fidalski \& Tormena (2005) foi obtida a partir de doses de calcário superiores ao dobro da necessidade de calcário, convencionalmente determinada pelo método de saturação por bases para elevá-lo a 70\%, na profundidade de $0,20 \mathrm{~m}$.

$\mathrm{O}$ suprimento de $\mathrm{Ca}$ e $\mathrm{Mg}$ está normalmente vinculado à aplicação de calcário. Os calcários calcíticos contém, em média, $45 \%$ de $\mathrm{CaCO}_{3}$, e os dolomíticos, em média, 20 a $40 \%$ de $\mathrm{MgO}$ (MALAVOLTA, 2006). Em decorrência da baixa quantidade de $\mathrm{MgO}$ existente nos calcários calcíticos, o uso sistemático de tais corretivos afeta a relação $\mathrm{Ca}: \mathrm{Mg}$ no solo. Portanto o objetivo foi avaliar os efeitos da relação $\mathrm{Ca}: \mathrm{Mg}$ no rendimento de diferentes espécies forrageiras e características químicas do solo.

\section{MATERIAL E MÉTODOS}

O experimento foi conduzido na Fazenda da Escola de Medicina Veterinária e Zootecnia da Universidade Federal do Tocantins, Campus de Araguaína, Norte do Tocantins, no ano agrícola de 2008 (Figura 1). As coordenadas geográficas de referência são: latitude Sul $7^{\circ} 13^{\prime} 48^{\prime \prime}$ e longitude Oeste $48^{\circ} 14^{\prime} 17^{\prime \prime}$. 


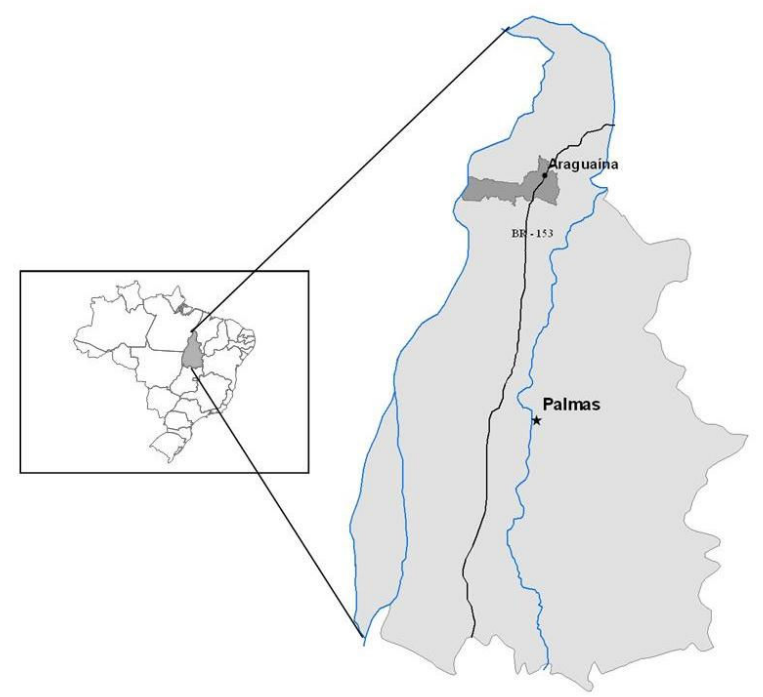

Figura 1. Localização espacial do município de Araguaína no Estado do Tocantins, Brasil

O clima, de acordo com a classificação de Koppen, é do tipo Aw, tropical chuvoso, com verão úmido. A precipitação média anual é de $1746 \mathrm{~mm}$ (Figura 2a). A caracterização da temperatura e a distribuição pluviométrica de 2008 encontram-se na Figura $2 b$ e $2 c$, respectivamente.

O solo da área utilizado foi classificado como Neossolo Quartzarênico Órtico típico (EMBRAPA, 2006), cujas características químicas e físicas $(0$ a $30 \mathrm{~cm})$, antes da instalação do experimento estão descritos na Tabela 1. O local de implantação do experimento nunca havia sido utilizado para fins agronômicos, sendo homogêneo com declividade de 0,2\%. Após a coleta o solo foi seco ao ar e passado em peneira de malha de $2 \mathrm{~mm}$ e analisadas. $O$ preparo do solo foi realizado de forma convencional com aração e duas gradagens.

$\mathrm{O}$ experimento foi distribuído em delineamento em blocos casualisados, em esquema fatorial $3 \times 5$, sendo três as espécies forrageiras (Brachiaria brizantha cv. Xaraés, Panicum maximum cv. Mombaça e Stylozanthes Campo Grande), e cinco relações Ca:Mg no calcário (01:01; 02:01; 04:01; 06:01 e 08:01), com quatro repetições por tratamento, totalizando-se 60 unidades experimentais de $16 \mathrm{~m}^{2}(4 \mathrm{x}$ $4 \mathrm{~m})$. Os tratamentos consistiram na aplicação de dose equivalente a $4 \mathrm{t} / \mathrm{ha}$ de calcário, (PRNT: 92\%), usando misturas de calcário calcítico $\left(\mathrm{CaCO}_{3}\right)$ e calcário dolomítico $\left(\mathrm{MgCO}_{3}\right)$, óxido de cálcio e magnésio para atingir as relações desejadas por tratamento.

Após quinze dias da aplicação dos corretivos foi realizada a adubação de implantação, com de $80 \mathrm{~kg}$ de $\mathrm{P}_{2} \mathrm{O}_{5}$ ha $^{-1}$ (superfosfato simples) e $60 \mathrm{~kg}$ de $\mathrm{K}_{2} \mathrm{O}$ ha $^{-1}$ (cloreto de potássio). Em seguida foi realizada a semeadura a lanço das espécies forrageiras (Brachiaria brizantha cv Xaraés, Panicum maximum cv Mombaça e Stylosanthes Campo Grande - Stylosanthes capitata e S. macrocephala). O controle de plantas daninhas antes da semeadura e após o estabelecimento das forrageiras foi realizado de forma manual. 

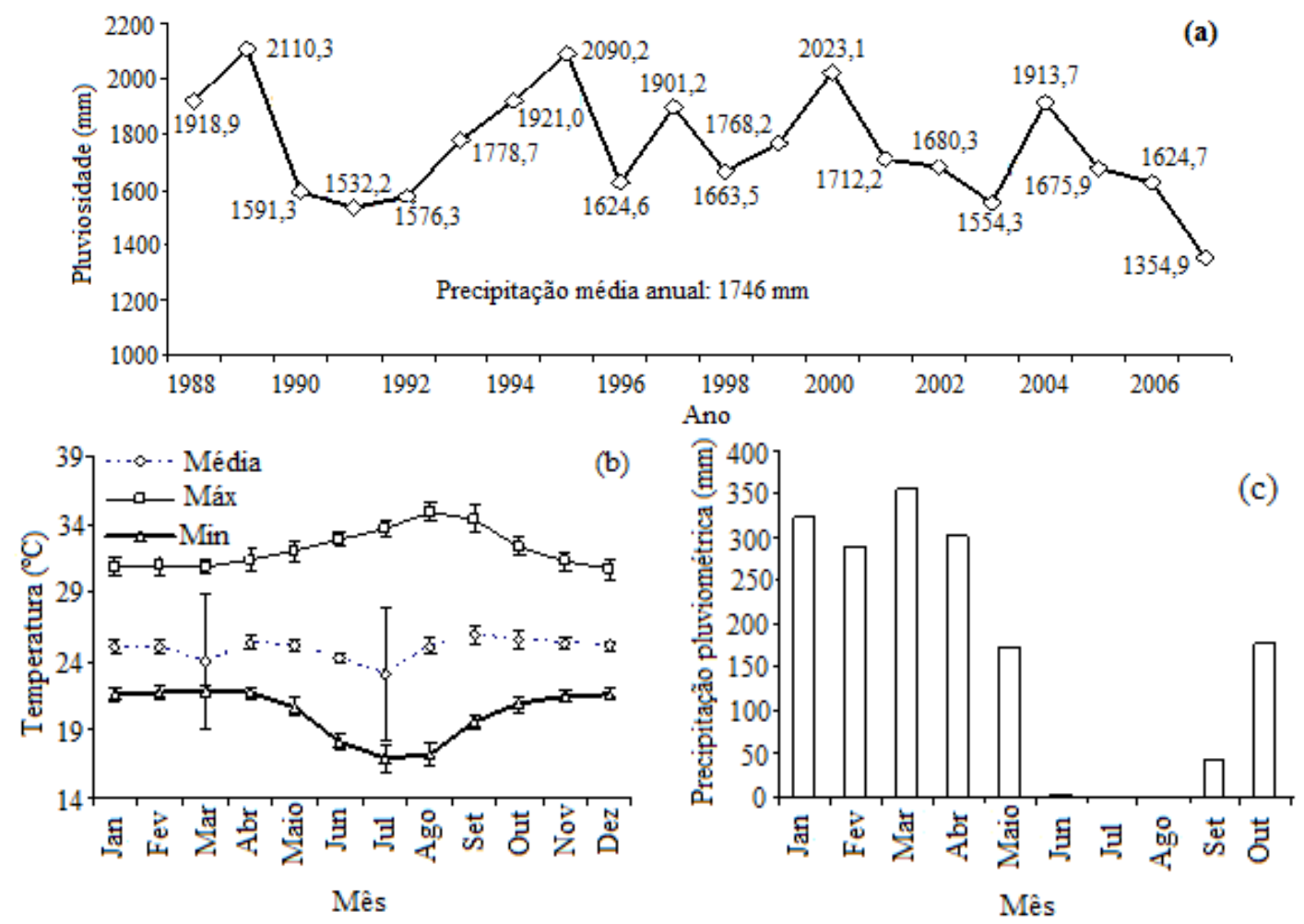

Figura 2. Caracterização da precipitação pluviométrica média anual - 1988-2006 (a), temperaturas (b) e distribuição da precipitação pluvial ao longo de 2008 (c), da área experimental.

Tabela 1. Características químicas e físicas do solo da área experimental nas diferentes profundidades

\begin{tabular}{lccccccccccc}
\hline Prof & $\mathrm{pH}$ & $\mathrm{P}$ & $\mathrm{K}$ & $\mathrm{Ca}$ & $\mathrm{Mg}$ & $\mathrm{Al}$ & $\mathrm{H}+\mathrm{Al}$ & \multicolumn{3}{c}{ Textura } & \multirow{2}{*}{$\mathrm{CT}$} \\
\cline { 1 - 10 } $\mathrm{cm}$ & $\mathrm{CaCl}_{2}$ & $\mathrm{Mg} / \mathrm{dm}^{3}$ & \multicolumn{4}{c}{$\mathrm{cmol}^{2} \mathrm{dm}^{3}$} & & Areia & Silte & Argila & \\
\hline $0-10$ & 4,57 & 0,98 & 0,025 & 1,19 & 0,38 & 0,28 & 2,84 & 92,1 & 4,3 & 3,6 & Areia \\
$10-20$ & 4,18 & 0,51 & 0,026 & 0,36 & 0,23 & 0,40 & 2,58 & 92,4 & 4,1 & 3,5 & Areia \\
$20-30$ & 4,15 & 0,41 & 0,026 & 0,18 & 0,31 & 0,56 & 2,73 & 94,0 & 3,5 & 2,5 & Areia \\
\hline
\end{tabular}

$\mathrm{CT}=$ classificação textural.

Foi efetuado o corte de estabilização a $10 \mathrm{~cm}$ do solo após o estabelecimento das gramíneas quando atingiu altura média de $40 \mathrm{~cm}$, a leguminosa não foi submetida ao corte de estabilização. Em seguida foi efetuada a primeira adubação nitrogenada em todos os tratamentos, inclusive na leguminosa Stylosanthes Campo Grande, com aplicação de $50 \mathrm{~kg} / \mathrm{ha}$ de $\mathrm{N}$ na forma de ureia. A adubação nitrogenada foi complementada após o primeiro corte de avaliação, resultando numa dose anual de $100 \mathrm{~kg}$ de N/ha.
As características agronômicas avaliadas foram a disponibilidade de matéria seca total (MSFT) e altura de plantas. Para a determinação da disponibilidade de forragem $(\mathrm{kg} / \mathrm{ha})$, foram efetuados dois cortes, sendo o primeiro aos 28 dias após o corte de estabilização e o segundo corte, com 28 dias após o primeiro corte. O quadro de amostragem foi de $1 \mathrm{~m}^{2}$, no ponto da altura média da forragem, sendo que todo o material no interior do quadro foi colhido a $10 \mathrm{~cm}$ do solo. Em seguida, todo o material colhido foi pesado para 
a determinação da massa. Após a amostragem, todas as parcelas foram cortadas a $10 \mathrm{~cm}$ do solo. As amostras pesadas foram colocadas em estufa de ventilação forçada com temperatura de $55^{\circ} \mathrm{C}$, para obtenção da MSFT. A altura de plantas $(\mathrm{cm})$ foi mensurada com trena, baseando-se da base do colmo a curvatura da última folha. Para a comparação dos dados de avaliação agronômica, foi utilizada a média dos dois cortes.

Após o último corte foram coletadas amostras de solos $(0-10 ; 10-20$ e 20 - $30 \mathrm{~cm}$ ) para análise químicas. As amostras foram secas ao ar, passadas por peneira de dois $\mathrm{mm}$ e analisadas quanto ao $\mathrm{pH}\left(\mathrm{CaCl}_{2}\right)$, cálcio $\mathrm{e}$ magnésio trocáveis, acidez potencial $(\mathrm{H}$ $+\mathrm{Al}$ ), fósforo disponível e potássio trocável, com extração com solução Mehlich 1 (EMBRAPA, 2009).

Os dados foram analisados pela análise variância (ANOVA). Testou-se inicialmente a interação entre os fatores, e quando não significativa, foram avaliados os tratamentos principais de forma separada. $\mathrm{O}$ efeito das espécies forrageiras quando necessário foram avaliados pelo teste de Tukey. Todas as análises foram realizadas a $5 \%$ de probabilidade.

\section{RESULTADOS E DISCUSSÃO}

$\mathrm{O}$ pH do solo não foi afetado pela interação da relação $\mathrm{Ca}: \mathrm{Mg}$ e forrageiras. $\mathrm{O} \mathrm{pH}$ foi de 5,31, 4,09 e 4,07 para as profundidades $0-10 ; 10-$ 20 e $20-30 \mathrm{~cm}$, respectivamente. Entretanto, esses valores foram alterados quando comparados com a condição inicial (Tabela 3), demonstrando o efeito da calagem, principalmente para camada superficial. Segundo Rheinheimer et al. (2000) o calcário adicionado na superfície do solo aumentou o $\mathrm{pH}$ e os teores de cálcio e magnésio, e diminuiu os teores de alumínio trocável na camada superficial.

O fósforo disponível não foi afetado pela interação entre a relação $\mathrm{Ca}: \mathrm{Mg}$ e forrageiras, e nem pelos fatores principais isolados $(\mathrm{P}>0,05)$. Os valores médios de $\mathrm{P}$ encontrados foram: 19,09; 10,98 e $6,48 \mathrm{mg} / \mathrm{dm}^{3}$, respectivamente, para as profundidades $0-10 ; 10-20 \mathrm{e}$ $20-30 \mathrm{~cm}$. Como no trabalho de Caíres \& Fonseca (2000) o maior acúmulo de fósforo disponível foi devido à aplicação na superfície, observando o mesmo para o presente estudo em todas as espécies forrageiras analisadas. As quantidades de fósforo disponível no solo foram alteradas quando comparados com a condição inicial do solo antes da calagem e adubação (Tabela 3), sendo atribuída a adição de fósforo na adubação de implantação.

Os valores de potássio foram alterados quando comparados com a condição inicial do solo antes da calagem e adubação, sendo atribuída a adição de potássio na adução de implantação. Entre as relações $\mathrm{Ca}: \mathrm{Mg}$ não foi observado nenhuma diferença $(\mathrm{P}>0,05)$ para o potássio no solo. Segundo Malavolta et al. (2006), esses elementos competem pelos mesmos sítios de absorção, sendo essa inibição do tipo competitiva.

Não foi observado interação entre a relação $\mathrm{Ca}: \mathrm{Mg}$ e forrageiras para $\mathrm{o}$ potássio, entretanto ao avaliar a forrageira de forma isolado observou-se diferença $(\mathrm{P}<0,05)$, conforme apresentado na Figura 3. Para a leguminosa Stylosanthes Campo Grande encontrou-se maiores concentrações de potássio no solo do que para as gramíneas Brachiaria cv. Xaraés e Panicum cv. Mombaça. Estes resultados podem ser atribuídos as diferentes características de absorção 
deste elemento pelas plantas. Os valores médios de $\mathrm{K}^{+}$encontrados foram: 0,06; $\quad 0,032$ e $0,024 \mathrm{cmolc} / \mathrm{dm}^{3}$, respectivamente, para as profundidades 0 $-10 ; 10-20$ e $20-30 \mathrm{~cm}$. Assim, como neste trabalho, Oliveira et al. (2001) não verificaram interação do potássio com a calagem, mas constataram que quantidades maiores de potássio podem aumentar a produtividade da leguminosa, no entanto, quando a relação $(\mathrm{Ca}+\mathrm{Mg} / \mathrm{K})$ foi maior que 36 prejudicou a disponibilidade. A relação $(\mathrm{Ca}+\mathrm{Mg} / \mathrm{K})$ foi maior no Panicum com 32 seguidos pela Brachiaria e Stylosanthes com 29 e 28 , respectivamente.

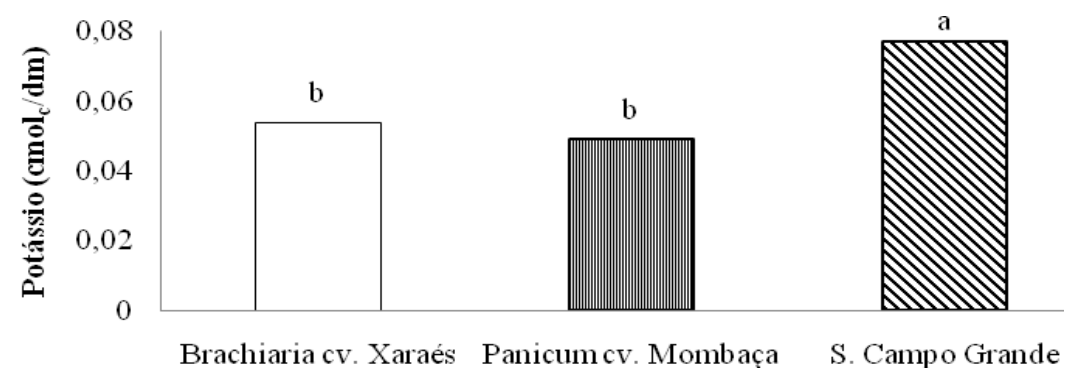

Figura 3. Concentração de potássio encontrado no solo em função das forrageiras Brachiaria cv. Xaraés, Panicum cv. Mombaça e Stylosanthes Campo Grande. Letras minúsculas iguais nas barras não diferem entre si ao nível de 5\% pelo teste de Tukey.

O cálcio não foi afetado pela interação relação $\mathrm{Ca}: \mathrm{Mg}$ e forrageiras, porém por ser um dos fatores principais isolados teve alteração $(\mathrm{P}<0,05)$. Quando analisado o fator cultura não houve diferença $(\mathrm{P}>0,05)$, entretanto, quando analisado o fator relação $\mathrm{Ca}: \mathrm{Mg}$ foi observado diferença $(\mathrm{P}<0,05)$, conforme mencionado na Figura 4, ocorrendo aumento na quantidade de cálcio com o aumento das relações $\mathrm{Ca}: \mathrm{Mg}$, isto pode ser atribuído ao aumento da quantidade do nutriente no corretivo do solo com o aumento da relação $\mathrm{Ca}: \mathrm{Mg}$. Os valores médios de cálcio encontrados foram: $1,11,0,24$ e $0,20 \mathrm{cmolc} / \mathrm{dm}^{3}$, respectivamente, para as profundidades $0-10 ; 10-20$ e $20-30 \mathrm{~cm}$. O excesso de cálcio em relação ao magnésio na solução do solo pode prejudicar a absorção desse último, assim como o excesso de magnésio pode prejudicar a absorção de cálcio, o mesmo ocorrendo com relação ao potássio (MALAVOLTA et al., 1997).

Não houve interação entre as relação $\mathrm{Ca}: \mathrm{Mg}$ e forrageiras para o magnésio e nem pelos fatores principais isolados $(\mathrm{P}>0,05)$. Os valores médios observados para magnésio foram: $0,32,0,1 \mathrm{e}$ $0,1 \mathrm{cmolc} / \mathrm{dm}^{3}$, respectivamente, para as profundidades $0-10 ; 10-20$ e $20-30 \mathrm{~cm}$. A inter-relação entre os nutrientes $\mathrm{Ca} \mathrm{e}$ $\mathrm{Mg}$ na nutrição vegetal está relacionada às suas propriedades químicas próximas, como o raio iônico, valência, grau de hidratação e mobilidade, fazendo com que haja competição pelos sítios de adsorção no solo, e na absorção pelas raízes. Como consequência, a presença de um pode prejudicar os processos de adsorção e absorção do outro, fato ocorrente para os íons $\mathrm{Ca}^{+2}$ e $\mathrm{Mg}^{+2}$ (ORLANDO FILHO et al., 1996). A alta relação de cálcio ao magnésio pode provocar a inibição da absorção do 
magnésio e potássio do solo, provocando diminuição da produção de matéria seca e altura de gramíneas (MEDEIROS et al. 2008).

A acidez potencial, alumínio, CTC (capacidade de troca catiônica) e V\% (saturação por bases) não foram afetados pela interação relação $\mathrm{Ca}: \mathrm{Mg} \mathrm{e}$ forrageiras, e nem pelos fatores principais isolados $(\mathrm{P}>0,05)$. Os valores médios encontrados foram: acidez potencial, 1,$85 ; 2,37$ e $1,81 \mathrm{cmolc} / \mathrm{dm}^{3}$; alumínio, 0,$06 ; 0,36$ e $0,33 \mathrm{cmol} / \mathrm{dm}^{3}$;
CTC, 3,48; 3,11 e 2,41 cmolc/dm 3 ; V\%, 45,$79 ; \quad 14,18$ e $13,86 \%$, para as profundidades $0-10 ; 10-20$ e $20-30 \mathrm{~cm}$, respectivamente. $\mathrm{O}$ teor mais elevado na V\% e CTC na camada superficial foram devido à aplicação do corretivo, pois este disponibiliza nutrientes como o fósforo além de aumentar o valor de $\mathrm{V} \%$ e CTC, pelo fato do calcário proporcionar maiores teores de cálcio e magnésio, menores teores de $\mathrm{Al} \mathrm{e}$ acidez potencial, provocando aumento da CTC e V\% (ARAÚJO et al., 2011).

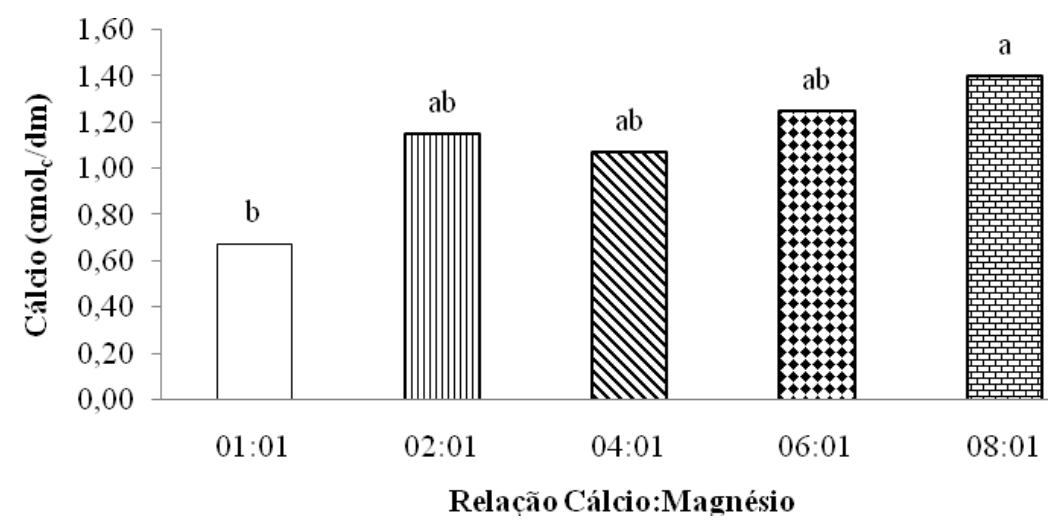

Figura 4. Concentração de cálcio em função das relações $\mathrm{Ca}: \mathrm{Mg}$ aplicadas no solo sob forrageiras Brachiaria cv. Xaraés, Panicum cv. Mombaça e Stylosanthes Campo Grande. Letras minúsculas iguais nas barras não diferem entre si ao nível de $5 \%$ pelo teste de Tukey.

Além da calagem as plantas possuem diversos mecanismos de tolerância à toxidade do alumínio, que se resume em duas classes: a primeira, que age no sentido de expulsar o alumínio depois de absorvido, a segunda, de evitar a absorção do elemento pelas raízes (HARTWIG et al., 2007).

Esses valores foram alterados quando comparados com a condição inicial do solo antes da calagem e adubação, sendo atribuída a aplicação do corretivo, porém o valor obtido não alcançou a saturação por base desejada $(80 \%)$, determinado pela forma de quantidade de calcário a ser utilizada. Segundo Fidalski \& Tormena (2005) a máxima alteração das características químicas do solo foi obtida a partir de doses de calcário superiores ao dobro da necessidade de calcário, convencionalmente determinada pelo método de saturação por bases para elevá-lo a $70 \%$, na profundidade de $0,20 \mathrm{~m}$.

A Brachiaria cv. Xaraés demonstrou maior resultado $(\mathrm{P}<0,05)$ de altura com $48,15 \mathrm{~cm}$, seguidos por Panicum cv. Mombaça e Stylosanthes Campo Grande, com 40,92 e 40,28cm (Figura 
5), respectivamente. A altura não foi afetado pela interação relação $\mathrm{Ca}: \mathrm{Mg}$ e forrageiras, entretanto seus fatores principais tiveram efeito significativo $(\mathrm{P}<0,05)$. Os valores médio da altura encontrados para o fator relação $\mathrm{Ca}: \mathrm{Mg}$ foram: 42,03; 48,55; 43,00; 41,97 e $40,02 \mathrm{~cm}$, respectivamente, para as relações Ca:Mg 01:01; 02:01; 04:01; 06:01 e 08:01, observando maior altura de plantas na relação $\mathrm{Ca}: \mathrm{Mg}$ de 02:01 (Figura 6).
Segundo Medeiros et al. (2008) a utilização de corretivos com alta relação $\mathrm{Ca}: \mathrm{Mg}$ acarreta diminuição da altura da planta, e de modo similar ocorre perda no potencial de produção de matéria seca, além de diminuir o teor de magnésio e potássio, sendo assim, aumentar o teor de cálcio, da planta pode criar um desequilíbrio nutricional, que irá se refletir em menor produtividade.

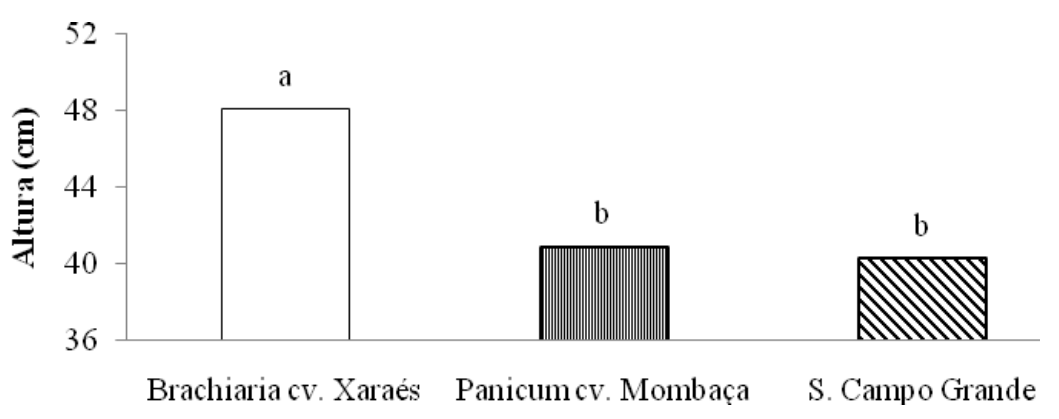

Figura 5. Altura de plantas em função das forrageiras Brachiaria cv. Xaraés, Panicum cv. Mombaça e Stylosanthes Campo Grande. Letras minúsculas iguais nas barras não diferem entre si ao nível de 5\% pelo teste de Tukey.

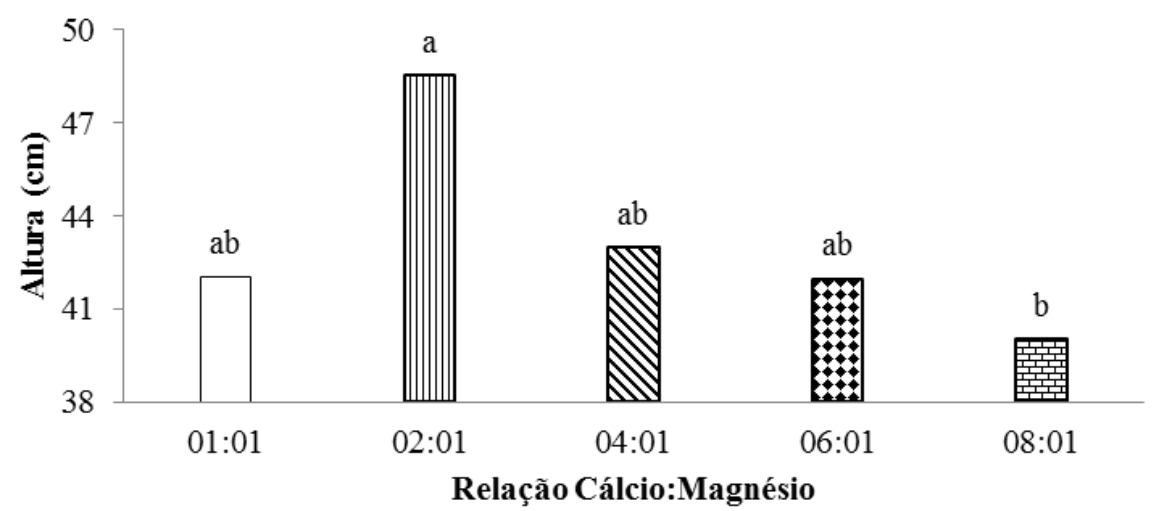

Figura 6. Altura de plantas em função das relações $\mathrm{Ca}: \mathrm{Mg}$ aplicadas no solo sob forrageiras Brachiaria cv. Xaraés, Panicum cv. Mombaça e Stylosanthes Campo Grande. Letras minúsculas iguais nas barras não diferem entre si ao nível de $5 \%$ pelo teste de Tukey. 
Quanto aos resultados da análise da produção de massa seca (Figura 7) ocorreu interação entre os fatores relação $\mathrm{Ca}: \mathrm{Mg}$ e forrageiras para produção de massa seca total $(\mathrm{P}<0,05)$. $\mathrm{Na}$ relação $\mathrm{Ca}: \mathrm{Mg}$ 01:01 foi observado que a Brachiaria cv. Xaraés e Stylosanthes Campo Grande obtiveram maiores resultados $(\mathrm{P}<0,05)$ que $\mathrm{o}$ Mombaça. Já na relação Ca: $\mathrm{Mg}$ 02:01 constatou-se que o Stylosanthes Campo Grande obteve maior resultado de MSFT $(\mathrm{P}<0,05)$ do que as culturas de Brachiaria cv. Xaraés e Panicum cv. Mombaça. A menor produtividade do Panicum em relação a Brachiaria pode ser devido a exigência nutricional do Panicum ser maior, expressando seu potencial produtivos em solos de maior fertilidade (MELO et al., 2009).

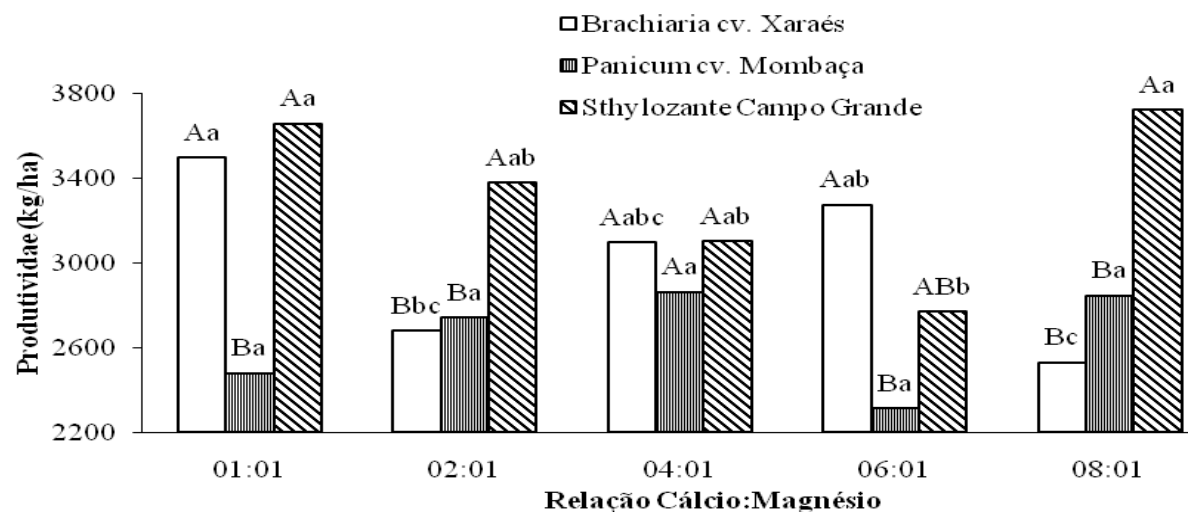

Figura 7. Produção de massa seca de plantas em função da interação entre forrageiras Brachiaria cv. Xaraés, Panicum cv. Mombaça e Stylosanthes Campo Grande e Relação Ca:Mg, letras maiúsculas iguais nas barras não diferem entre as forrageiras ao nível de 5\% pelo teste Tukey, letras minúsculas iguais nas barras não diferem entre as relações $\mathrm{Ca}: \mathrm{Mg}$ ao nível de 5\% pelo teste Tukey.

Observou-se que na relação $\mathrm{Ca}: \mathrm{Mg}$ 04:01 não apresentou diferença $(\mathrm{P}>0,05)$ entre as culturas analisadas. $\mathrm{Na}$ relação $\mathrm{Ca:Mg} \mathrm{06:01} \mathrm{a} \mathrm{Brachiaria}$ cv. Xaraés obteve maior produção de MSFT $(\mathrm{P}<0,05)$ que o Panicum cv. Mombaça e não observando diferença entre o Stylosanthes Campo Grande, constatando que o Stylosanthes Campo Grande não obteve diferença na MSFT do Panicum cv. Mombaça.

Observou-se maior produção de MSFT no Stylosanthes Campo Grande $(\mathrm{P}<0,05)$ que as culturas de Brachiaria cv. Xaraés e Panicum cv. Mombaça, na relação $\mathrm{Ca}: \mathrm{Mg}$ de 08:01. Em termos de produtividade o Stylosanthes e o
Panicum estão mais adaptados a diferenças na relação $\mathrm{Ca}: \mathrm{Mg}$ do que a Brachiaria. O Stylosanthes teve perdas de produtividade apenas na relação 6:1, enquanto que no Panicum não foram verificadas diminuição da produtividade. Constatando-se que a Brachiaria cv. Xaraés obteve maior $(\mathrm{P}<0,05)$ produção de MSFT na relação Ca:Mg 01:01 do que as relações $\mathrm{Ca}: \mathrm{Mg} \mathrm{02:01}$ e 05:01, entretanto não observando diferença entre as relações $\mathrm{Ca}: \mathrm{Mg}$ de 04:01 e 06:01. Foi observado que a relação $\mathrm{Ca}: \mathrm{Mg}$ 04:01 obteve maior produção de

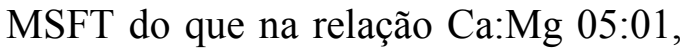
todavia igualando $(\mathrm{P}>0,05)$ as relações Ca:Mg 02:01 e 06:01. 
A variação da produtividade não foi relatada em trabalhos que avaliaram as relações de $\mathrm{Ca}: \mathrm{Mg}$ para diversas culturas, tanto leguminosas quanto gramíneas. Oliveira \& Parra (2003) não conseguiram identificar mudanças na produtividade de feijoeiro em seis relações diferentes de $\mathrm{Ca}: \mathrm{Mg}$ e relatam que diversas outras culturas não sofreram nenhum efeito quanto a relação $\mathrm{Ca}: \mathrm{Mg}$ do corretivo utilizado. Entretanto, Medeiros et al. (2008) verificaram diminuição da produtividade no milho à medida que as relações de $\mathrm{Ca}: \mathrm{Mg}$ aumentaram. Porém tanto Medeiros et al. (2008) quanto Oliveira \& Parra (2003) observaram alterações na composição química de cálcio, magnésio e potássio do tecido vegetal.

A relação $\mathrm{Ca}: \mathrm{Mg}$ influenciou o desenvolvimento e produtividade das forrageiras entretanto, não se obteve um comportamento coerente que indicasse a tendência de resposta das plantas ao aumento ou redução da relação $\mathrm{Ca}: \mathrm{Mg}$.

As diferentes forrageiras (Capim Xaraés, capim Mombaça e estilosantes Campo Grande) foram semelhantes em relação as propriedades química do solo, porém as relações $\mathrm{Ca}: \mathrm{Mg}$ alteraram algumas propriedades químicas do solo (cálcio e potássio).

A aplicação das relações com crescentes proporções entre cálcio e magnésio aumentou o teor de cálcio na capacidade de troca cationnica do solo e reduziu os de magnésio, criando desbalanceamento dos nutrientes no solo.

\section{AGRADECIMENTOS}

Ao CNPq pelo apoio com a) Bolsas no País / Iniciação Científica - Edital MCT/CNPq $n^{\circ}$ 12/2010 - IC, b) Edital MCT/CNPq 10/2010 Apoio Técnico / Edital MCT/CNPq 10/2010 AT-NS (Nivel Superior); e c) Bolsas no País /
Produtividade em Pesquisa - PQ - 2009Orientador COAGR/CGAPB/DABS). Programa de Apoio a Núcleos de Excelência PRONEX/SECT/CNPq. A CAPES. A Caltins pelo apoio na doação do calcário. Apoio fundamental para realização deste trabalho.

\section{REFERENCIAS}

ARAÚJO, A.S.; SILVA, J.E.C.; SANTOS, A.S.; SILVA NETO, S.P.; DIM, V.P.; ALEXANDRINO, E.

Substituição de nitrogênio por esterco bovino na produtividade de forragem e qualidade do solo. Revista Brasileira de Saúde Produção Animal [online], v.12, n.4, p. 852-866, 2011.

BARRETO, P.M.; SANTOS, A.C.; GUIMARÃES JÚNIOR, M.P.A.; BRITO, S.S.; TERRA, T.G.R.; LEAL, T.C.A. Relações Ca:Mg nas características agronômicas do Brachiaria brizantha cv. MG-4. Pubvet, v.2, n.38, 2008.

CAÍRES, E.F.; BLUM, J.; BARTH, G.; GARBUIO, F.J.; KUSMAN, M.T. Calagem na superfície em sistema de plantio direto. Revista Brasileira de Ciência do Solo, v.24, n.1, p.161-169, 2000.

CAÍRES, E.F.; FONSECA, A.F. Absorção de nutrientes pela soja cultivada no sistema de plantio direto em função da calagem na superfície. Bragantia, v.59, n.2, p.213-220, 2000.

EMPRESA BRASILEIRA DE PESQUISA AGROPECUÁRIA EMBRAPA. Centro Nacional e Pesquisa em Solos. Sistema Brasileiro de Classificação de Solos. Brasilia: EMBRAPA-SPI / Rio de Janeiro: EMBRAPA-Solos, 2006. 306p. 
Rev. Bras. Saúde Prod. Anim., Salvador, v.14, n.3, p.460-471 jul./set., $2013 \quad$ http://www.rbspa.ufba.br ISSN 15199940

EMPRESA BRASILEIRA DE

PESQUISA AGROPECUÁRIA -

EMBRAPA. Manual de análises

químicas de solos, plantas $\mathrm{e}$

fertilizantes. Brasília: EMBRAPA

Solos/EMBRAPA Informática

Agropecuária/EMBRAPA Comunicação

para Transferência de Tecnologia, 2009. $627 p$.

FIDALSKI, J.; TORMENA, C.A.

Dinâmica da calagem superficial em um

Latossolo Vermelho distrófico. Revista

Brasileira de Ciência do Solo, v.29, n.2, p.235-247, 2005.

FREIRIA, A.C.; MANTOVANI, J.R.; FERREIRA, M.E.; CRUZ, M.C.P.; YAGI, R. Alterações em atributos químicos do solo pela aplicação de calcário na superfície ou incorporado.

Acta Scientarum. Agronomy, v.30, n.2, p.285-291, 2008.

HARTWIG, I.; OLIVEIRA, A.C.; CARVALHO, F.I.F.; BERTAN, I.; SILVA, J.A.G.; SCHMIDT, D.A.M.; VALÉRIO,I.P.;MAIA, L.C.; FONSECA, D.A.R.; REIS, C.E.S. Mecanismos associados à tolerância ao alumínio em plantas. Semina, v.28, n.2, p.219-228, 2007.

MALAVOLTA, E.; VITTI, G.C.; OLIVEIRA, S.A. Avaliação do estado nutricional de plantas: princípios e aplicações. Piracicaba: Potafos, 1997. $319 \mathrm{p}$.

MALAVOLTA, E. O futuro da nutrição de plantas tendo em vista aspectos agronômicos, econômicos e ambientais. Piracicaba, SP: IPNI, 2008. p.1-10. (Informações Agronômicas, 121).

MALAVOLTA, E.; MORAES, M.F.; LAVRES JÚNIOR, J.; MALAVOLTA, $\mathrm{M}$. Micronutrientes e metais pesados essencialidade e toxidez.. In:
PATERNIANI, E. (Ed.). Ciência, agricultura e sociedade. Brasília: EMBRAPA Informação Tecnológica, 2006. p.117-154.

\section{MALAVOLTA, E. Manual de nutrição} mineral de plantas. São Paulo: Agronômica Ceres, 2006. 638p.

MEDEIROS, J.C.; ALBUQUERQUE, J.A.; MAFRA, A.L.; ROSA, J.D.; GATIBONE, L.C. Relação cálcio:magnésio do corretivo da acidez do solo na nutrição e no desenvolvimento inicial de plantas de milho em um Cambissolo Húmico Álico. Semina, v.29, n.4, p.799-806, 2008.

MELO, J.C.; SANTOS, A.C.; ALMEIDA, J.A.; MORAES NETO, L.R. Desenvolvimento e produtividade dos capins Mombaça e marandu cultivados em dois solos típicos do Tocantins, com diferentes regimes hídricos. Revista Brasileira de Saúde Produção Animal [online], v.10, n.4, p.786-800, 2009.

MIRANDA, L.N.; MIRANDA, J.C.C.; REIN T.A. Utilização de calcário em plantio direto e convencional de soja e milho em Latossolo Vermelho. Pesquisa Agropecuária Brasileira, v.40, n.6, p.563-572, 2005.

OLIVEIRA, A.O.; CARMELLO, Q.A.C.; MASCARENHAS, H.A.A. Disponibilidade de potássio e suas relações com cálcio e magnésio em soja cultivada em casa de vegetação. Scientia Agricola, v.28, n.2, p.329-335, 2001.

OLIVEIRA, E.L.; PARRA, M.S.

Resposta do feijoeiro a relações variáveis entre cálcio e magnésio na capacidade de troca cátions de Latossolos. Revista

Brasileira de Ciência do Solo, v.27, n.5, p.859-866, 2003. 
ORLANDO FILHO, J.O.;

BITTENCOURT, V.C.; CARMELLO,

Q.A.C.; BEAUCLAIR, E.G.F. Relações

$\mathrm{K}, \mathrm{Ca}$ e $\mathrm{Mg}$ de solo areia quartzosa e produtividade da cana-de-açúcar.

STAB, v.14, n.5, p.13-17, 1996.

RHEINHEIMER, D.S.; SANTOS, E.J.S.; KAMINSKI, J.; BORTOLUZZI, E.C.; GATIBONI, L.C. Alterações de atributos do solo pela calagem superficial e incorporada a partir de pastagem natural. Revista Brasileira de Ciência do Solo, v.24, n.4, p.797-805, 2000.

Data de recebimento: $24 / 03 / 2013$

Data de aprovação: 10/09/2013 